\title{
Deepening Democratic Culture in Nigeria: What Role(S) For New Media?
}

\author{
Ibrahim O. Salawu \\ Department of Global Studies and Social Science, Political Science Unit, \\ Kwara State University, Malete, Nigeria.
}

\begin{abstract}
The complementary role which New Media has come to play has increased the level of complexity of Nigerian Politics. This can be attributed to the increase in information flow, especially at the informal level which has bridged the hitherto wide informational gap between government and the governed. This is better appreciated considering Nigeria's political history which is dotted with several military incursions into governance and the attendant emasculation of all informational avenues including the Press. This paper examines the theoretical basis for New Media, using a descriptive analytical method. It also tries to rationalize the need for new media in a democracy and the inherent challenges using Nigeria's experience. However, the paper concluded that the pervasive nature of poverty as experienced in the country as well as the weak regulatory framework that should drive access and content generation, has being a major clog in the wheel of a robust New Media penetration in Nigeria. This regrettably is the fate of most developing and underdeveloped polities.
\end{abstract}

Key Words: New Media, Democratic consolidation Social Media, Democratization, Democracy.

\section{Introduction}

As the communications landscape gets denser, more complex and more participatory, the networked population is gaining greater access to information, more opportunities to engage in public speech and enhanced ability to undertake collective action in the political arena(shirky:2011:29). The global reach, instantaneous speed and unlimited information now available through various terminals i.e. internet, cable TV, mobile phone using different platform facebook, twitter, you-tube and the likes has in no small measure affected governance especially as it relates to spread of information which could be deployed for socio-political mobilization and cohesion.

The apparent foot-dragging which greeted the idea and subsequent emasculation of the processes that should have accelerated the processes of making some of these avenues for self expression readily accessible on different communication spectrums under successive military governments in Nigeria has delayed an in depth analysis of its utility in governance and talk less of democratic sustenance.

Extant literature is replete with analysis of the role of the media in strengthening democracy in Nigeria. However, there has been a dearth of literature in the area of measuring the democratic value of the digital revolution in Nigeria. The digital revolution sweeping across the globe has in no small measure narrowed and played down the gap that hitherto existed between time, space and distance in conventional media practice and has in no small measure redefined the relationship between government and the civil populace in developing democracies like Nigeria. It is believed that any further delay in nurturing this global trend through an initial qualitative analysis and suggesting to policy makers how fostering the relationship between New media and Politics in Nigeria must be handled could be an albatross for the already fragmented entity like Nigeria.

\section{Framework Of Analysis: Optimism Vs Pessimism.}

The virtual political system has quickened the pace at which governments and civil societies adapt to information technologies and the future openings for active citizenship and civic engagement. Scholars are however divergent in their views on the emerging trend-"New Media". The point of disagreement started from the nomenclature- "New". It is believed that what is new today will become 'Old' tomorrow. Therefore, conceptual clarification to them will be incomplete without a substitution of the term 'New Media' with a more pragmatic phrase 'social Media'. Cyber optimists have been unanimous in acknowledging digital revolution as perhaps the most important development of this generation and even our lifetimes (Norris: 2001).To her, limitless information available via the internet and its ancillaries has a potential to imbue in the public a vast amount of knowledge about public affairs, more articulate in expressing their views via e-mails, chartrooms and more active in community affairs (Schwartz 1996). In situating New Media properly within the realms of politics (Norris: 2001:303), posits that as a virile means of information dissemination, New Media provides a two-way channel of communication between the citizens and other gate keepers within political system such as 
political parties, social movements, interest groups and even the conventional news media as well as public officials and agencies of government.

To these Cyber optimists, information of international and global relevance on governance can be made readily accessible and to a large extent will have a knock-on effect in political participation, civic engagement, campaign analysis, mobilization and the building of coalitions around policy problems and advocacy.

Amplifying earlier positions on the relevance of New Media, Howard Rheingold (1993), Ian Budge (1996) advanced arguments to reinforce Benjamin Barber's (1984) theory on direct Democracy. New Media to them has evolved a platform that allows opportunities for citizens' deliberation and direct decision-making through online referendums and other initiatives all geared towards devolution and grass roots mobilization to fix local problems.

In tandem with this notion Fayemi (2012) in a perceptive article titled "Digital Governance in Nigeria: going beyond the hype, The Ekiti State Governments' Digital Media Case study and Lesson for the Public Sector", eruditely submitted that the tools of new media complements its capability as tools for enhancing information and interflow of communication across numerous actors which can spark up swift social change. This change is reverberated in daily routines of e-commerce, e-publishing, e-learning, e-voting etc. All of these to Fayemi, who is also the incumbent Governor of Ekiti State southwest Nigeria, will certainly continue to serve as a key driver of employment opportunities and economic growth even in more advanced Democracies. This is a position equally supported by other economic pundits in Nigeria who have been seeking for alternative avenues for quick-wins in the area of employment generation and poverty alleviation.

\section{Pessimism}

The pessimistic disposition of some political analysts regarding new media, especially in Nigeria is hinged on its volatility. The digital culture as exemplified by the internet, websites, computer multimedia, DVD etc can be at once liberating and equally capable of spinning out of control ( see Fayemi: 2012).The institutional linkage between the internet-generated democratic revival has been called to question by the skeptics who while acknowledging the utility of the new media as a valuable supplement to traditional forms of communication, are yet to fathom how established parties and interest groups would allow the new media to flourish at the expense of heavy weight media corporations who have always reasserted their predominance. This conservative disposition is also re-echoed by R.W. Machesney(1999:182-185) who was quick to cite the American situation, where mass media giants like the CNN and The Newyork Times were subtly persuaded into focusing more on entertainment and by so doing, reducing its utility as a viable platform for political mobilization. The mediated forms of political communication which the cyber culture breeds may be an inadequate substitute for the traditional face-to-face political networking as alluded to by Putnam (2000).This has been a major challenge for New Media as an instrument of social cohesion as against the overtly ambitious disposition of the optimists who see New Media to be a 'sine qua non' for viable political relationships and veritable platform for a bottom-up civic engagement.

It is however not surprising that socio- economic biases which are evident for decades in conventional mass media seem unlikely to disappear even with the new media revolution, this has been argued as capable of spinning a negative salutary effect on the agenda setting role of the media whether conventional or 'new'. Towing this line of thought, Richard Davis \& Diana Owen: 1998) submitted that

....The global and social divides in internet access mean that technological resources remain far from equally distributed and online politics may thereby amplify the voice of the affluent and well educated, with prior interest, cognitive skills and technical ability to utilize new forms of communication, but may further marginalize the apathetic and the under privileged...

Political participation accordingly will typically be the views of communities dominated by likeminded groups which merely reinforce views but not typically exchanging ideas. The resultant effect here would definitely breed a scenario in the political landscape where deliberative inclinations are nurtured in line with the discourse of liberal Democracy.

\section{The Nigerian Political Climate}

The Nigerian political scene has further amplified the views expressed above. Interestingly, it has provided avenues which make it easier to gauge the mood of key political stakeholders on the role of New Media in a democracy. What is reassuring nevertheless is that an analysis of outcome gives a mixed reaction which consistent with the earlier review in this paper.

In a recent address by David Mark, Nigeria's Senate President titled "Role of the Media and Good Governance in Nigeria". The speech was tainted with a lot of pessimism regarding a flagrant flourishing of 
New Media and the social content. As a follow up, he called for a regime of censorship since according to him, social Media do not have room for "rebuttal". His reservations are better copiously stated below:

......The emergence of social media like facebook, twitter, blackberry messenger, YouTube etc have changed the face of media practice by making information sharing easier, faster and quicker. But this is not without its demerits. Social media has become a threat to the ethics of media practice and good governance because of its accessibility and absolute freedom. Every freedom carries a responsibility. Even in advanced democracies, where we all agree that good governance is practiced, there is no absolute freedom........

What seem like a blend of the two schools of thought was provided by Jibrin Ibrahim who is the Director, Center for Democracy and Development in Nigeria while addressing a conference May 2012 on the topic,' New Media and Governance: Tools and Trends". His submission is below may not be surprising because of his civil society background. To him,

. New Media tends to cater for society's trend towards limited sound bites and short attention spans. New Media often does not provide context analysis or a deeper understanding of issues. However it has increased awareness in governance especially on the Federal Budget when figures of the President's food Budget were released......

To complement this, Jega (2012) highlighted the gains of New Media in election administration in Nigeria to include transparency, swift feed backs for security intervention and above all civic mobilization of the Youths for election. Prof. Jega, the incumbent chairman of the electoral commission in Nigeria who has been globally commended for conducting the 2011 general elections in Nigeria in a far better manner than the country had experienced since the disengagement of the Military from governance, attributed the internationally acclaimed improvement in election administration partly to the novel New Media revolution. He was quick to add though, that New Media in Nigeria is fraught with the challenges of misinformation, illiteracy, narrowed scope etc.

\section{Exploring The New Media And Democratization Nexus}

The enormity of the task of civic engagement, political participation vis a viz media access cannot be less daunting. This challenge is even more profound in newer democracies. Nigeria, with just above a decade of representative democracy is not an exception. A unique feature in Nigeria's experience is that the New Media revolution gathered momentum almost at the same time and pace with the military disengagement from politics in the country. Statistics show that Nigeria has witnessed a phenomenal growth in online activities from 200,000 internet users in December, 2000 to over 43 million people maintaining on line presence in January 2012. This figure towers above other countries within the continent having higher GDPs and GNPs. Egypt (17 millionusers), South Africa (5 million), Morocco (10.4 million users), Algeria (4.7 million) (www.internetworldstarts.com/af/index)

It will not be out of place to conclude that Nigeria's renewed attempt at democracy was borne into the "New Media" milieu. This forms the basis for state and other non-state actors including, but not limited to the civil society to harness a critical mass of informed minds for social-political transformation and electoral integrity drive. This is more apt for Nigeria with a history of low level of transparency in the conduct of its affairs including elections. The apparent lack of transparency in electoral matters makes rigging, ballot box snatching, violence and other forms of corruption integral parts of the electoral process. This is a myth which New Media and its ancillaries dealt a great blow in the 2011 general elections in Nigeria. This position is further reechoed by civil society organization including the National Democratic Institute in her final report on the elections thus:

More than in 2007, New Media played a prominent role in the elections.

Access to internet and mobile phones were limited mainly to the urban centers, but still contributed to wider popular participation in elections. Nigerian youths in particular used blogs, social forums and online networking sites to disseminate information, discuss election related issues, mobilize to vote and reports results and incidents. Candidates and parties also launched significant outreach efforts through social media and used text messaging in their campaigns. Closer to elections, INEC started updating its website more regularly and began using Twitter, Facebook, and SMS to gather information on the election process. (NDI: 2011:43).

Quite a number of views have been expressed on the correlation between New Media and democracy. (See Norris, 2001) identified three pertinent rhetorical postulates through which New Media can accentuate democratization. These are

i. Knowing the type of (political) institutions moving online. 
ii. Assessing the functions of these political websites for maximizing transparent and interactive communication.

iii. Explaining the rise of digital politics and in particular how far does socio economic, technological and political development drive these processes.

These positions are predicated on the notion that, New Media revolution to a large extent helps to broaden the political landscape through which digitalization of the conventional media platforms promotes an atmosphere where political stake holders can freely and spontaneously interact and the "pulse" of the citizenry felt or vice versa, to the extent that those institutions originally meant to act as gate keepers, who play an important role in the agenda setting and agenda building process can equally channel information about government back to the public. The greatest challenge to this move in contemporary Nigeria is the paucity of multimedia content which unfortunately, necessitated a fall-back on the traditional media for content generation. The reason for this (see Fayemi: 2012 ) stems from the lack of ownership, accountability and the attendant lack of performance indices for measuring return on investment in this direction, a situation that has always rendered the New Media as a postscript in the process of civic engagement within the democratic landscape.

\section{Challenges To New Media Penetration In Nigeria}

Press freedom, an in alienable component of any democracy or civil rule has been almost with impunity been trampled upon by successive military junta and even civilian governments in Nigeria. The byeproduct of this is a civilian administration in 1999, which in addition to President Obasanjo's military background believe in muffling information flow. This accounts for his inability to see to the passage of the freedom of information act, which ordinarily is expected to provide a better ambience for the flourishing of New Media. The same tendency is being canvassed today by Senate President David Mark, another retired General now occupying the highest position in the legislative arm of government- the Senate. His recent out bursts on social media censorship is nothing but a reflection of the body language of the ruling elite in Nigeria, who have spent the better part of their leadership apprenticeship under the anachronistic military rule.

The New media revolution at this point in time of Nigeria's political development is almost a belated welcome relief! This is definitely in tune with the global trend where media pluralism and democratization have become the norm. It is activism which reality brings to our door step. A plural media according to Aliagan (2006) will create a sustainable democratic culture. To him conventional media in Nigeria have to a greater extent limited itself to promoting democratic politics at the expense of engendering democratic culture. This is one lacuna which New Media must seek to fill.

The pervasive nature of poverty in this part of the world has also constituted a major clog in the wheel of progress of the New Media pundits. Despite the impressive leap in the statistics of internet users in Nigeria between the year 2000 and 2012 and as a matter of fact by extension, domiciling $32 \%$ of the internet users in the entire African continent, (www.internetworldstarts.com/af/index) clearly illustrates the prospects for the New Media and its ancillaries as a veritable tool for socio political mobilization in Nigeria. This however, has not aided penetration. It is common knowledge that the distribution and the profile of users as illustrated above and as optimistic as it looks is skewed primarily to the economically advantaged class within the country. This has debilitating effects on the utility of the New Media as a tool for political mobilization especially in election administration. It equally re echoes Mohammed (2004) that New Media is a preserve of polities who are already rich in informational resource.

\section{New Media: A Revolutionary Tool For Democratic Consolidation}

Despite accusations of exhibiting the trappings of elitism cum neo-colonial posturing of the anti New Media revolution epitomized by the argument of the skeptics earlier advanced. The invaluable potentials of the various spectrums provided by New Media through which civic engagement can be established, conducted and regulated cannot be over emphasized. Without recourse to the global hype, it has remained the basis for the claim of the world being a "global village". Viewed from the Nigerian context, the teething problems retarding the pace of democratization and institutional reinforcement can be addressed through a broad spectrum of opportunities provided by the New Media especially in areas where the conventional media has proven to be inadequate or obsolete.

The liberalization of information dissemination and the spawning alternatives views which is one of the hallmarks of civilized society as alluded to by Sawanti (2002, in Ojo E.O 2006: 77) is a major contribution to democratic sustenance in Nigeria. The spread of new technologies which has come to redefine relationships between government to government at one end and between government and the governed on the other hand has made information and more importantly opinion molding (Private \& Public) at the mercy of a click on any of the devices which the internet for instance provides. This has a far reaching implication for democratic culture and politics (See Mohammed 2004: 469). 
The seamless reach provided by new media in a democracy and its attendant power of mobilization, opinion formation and more specifically, civic engagement is more pronounced in electioneering campaigns. Leading the pack is President Barak Obama, of the United States of America en route his Presidential election victory of 2008 , used the internet effectively to his advantage, particularly in the area of fundraising towards winning the presidential election, where he was reported to have raised a whooping sum of thirty-two million USD in January 2008 from over two hundred and fifty thousand contributors (techcrunch.com).

Closer home, President Goodluck Jonathan was able to access a sizeable chunk of the Nigerian voting public on the social media- Facebook which culminated in his publishing of two books; "My Friends and I" and "Bring Back the Book" detailing the feedbacks he garnered during the electioneering campaigns of 2011 and stressing the need to re- ignite the dwindling reading culture among Nigerians and particularly the youths who form the bastion of Facebook users.

At the other end, it is apt to add that the same New Media platforms used by these leaders can be used for dishing out constructive criticisms and sometimes disparaging accusations against policy directives of government. A case in point was the fuel subsidy removal protests of January 2012 in Nigeria and government's eventual shift of ground by reversing pump price to sixty seven naira can be attributed partly to the enormity of pressure mounted through the social media, Facebook, twitter et al on government and more importantly, the effect of the various social media anchored on the internet in the sustenance of the protests for more than a week. This is a development which is unprecedented in the annals of civil right protests in Nigeria (Amaefule: 2012). The social Media was a wakeup call for political leadership at all levels to respond albeit reluctantly before the situation escalates further while also preempting the events especially in the western part of the country from snow-balling into what has now been dubbed "Arab spring" where New Media singularly became a rallying point for mass mobilization (social capital.wordpress.com).

International relations and national identities are two broad areas where developing countries have been impacted by new media technologies. Nigeria and other developing polities do not have the same amount of access to informational resources required to combat global inequalities. These challenges are better highlighted in (Ijoumas and Suprenant: 1987, Shaheed 2004) thus:

....These issues of representation and self presentations have been of particular significance to small developing states that are trying to compete for attention in cyberspace forms part of the ongoing struggle of many developing countries to combat global inequalities....

\section{Conclusion And Recommendation}

The complementary role which the New Media and its ancillaries such as internet, websites, computer multi-media, DVDs, video games, CD-ROMs etc have come to play alongside the convectional media like radio, television and newsprints magazines cannot be over emphasized. Nigeria as a member of the global community must urgently latch on to the opportunity of a continuous, seamless interaction between governments at different levels in the federal structure and governments and the citizenry at the other end for a mutually rewarding civil engagement which is a hall mark of a democracy and civil rule. Gauging the pulse of every strata of the society in whatever policy direction, government's actions or inactions versus spontaneous reactions of the people irrespective of distance, time and space are the priceless value proposition and cutting edge which New Media enjoys its monopoly till date.

To buttress the claim of a worldwide wave and the need for serious attention by state and non- state actors particularly underscores the United States of America's commitment to internet freedom under Clinton's administration and its subsequent provision of funds to bolster this vision of fighting censorship across the globe and foreign relations generally(Shirky:2011).

However, extant Media laws must be reviewed carefully in such a manner that would not portray Nigerian government as being authoritarian while checkmating abuses by New Media adherents in the country to forestall its use for the promotion of terrorism and other malady against government and amongst the citizenry. These can be achieved by a review of existing media regulatory framework for New Media access, content generation and standardization in Nigeria.

\section{References}

[1]. Aliagan I.Z (2006)The Press and the Challenges of Democratic Development in Democracy and Development in Nigeria; Conceptual Issues and Democratic Practice, Saliu H. (eds ), Concept Publications, Lagos.

[2]. Benjamin Barber (1984), Strong Democracy: Participatory Politics for a New Age, University of California Press.

[3]. Clay Shirkly (2011), The Political Power of Social Media; Foreign Affairs, volume 90(1), January / February, 2011

[4]. Howard Rheingold (1993) Virtual Community: Homesteading on the electronic frontier, (electronic version),www.rheingold.com/vc/book/intro.html.

[5]. Ian Budge (1996) The New Challenge of Direct Democracy, Polity Press, Oxford.

[6]. Jega A. (2012) Nigeria Elections and New Media: Moving Forward; Conference Report on New Media and Governance (14-15 $5^{\text {th }}$ May, 2012) published by the Yaradua Foundation, Abuja. 
[7]. Jibrin Ibrahim (2012), Conference Report on New Media and Governance (14-15 $5^{\text {th }}$ May, 2012) published by the Yaradua Foundation, Abuja.

[8]. Machesney, R. W. (1999) Rich Media, Poor Democracy; Communication Politics in Dubious Times Chicago: University of Illinois Press.

[9]. Mohammed Shaheed (2004) Self-presentation of small developing countries on the World Wide Web: a study of official websites, New Media \& Society, Sage Publications, London. Vol6 (4)469-486

[10]. Sawanti P.B (2002)Mass Media and Democracy: A Global View in Ojo E.O(2006) Press Freedom and Democratic Development, Conceptual Issues and Democratic Practice,Saliu H. et al,Concept Publications, Lagos.

[11]. Schwartz Tony(1996)Media and Value, Published by Centre for Media and Literacy, Malibu, Canada.

[12]. Tjoumas, R, and T.T Surprenant(1987), Trends in International Informational Issues. Communication Quarterly 35(3).

\section{Newspapers/Magazines/Blogs}

National Democratic Institute Final report on the 2011 elections in Nigeria. Available at:

http://www.ndi.org/files/NDI\%20Final\%20Report\%20on\%20the\%20Nigeria\%202011\%20Electionsnew_Part1. pdf

The Punch Newspapers, January 2012.

www.internetworldstarts.com/af/index

Michael Arrington;www.Techcrunch.com/2008/02/04

www.social capital.wordpress.com).

http://www.informationnigeria.org/2012/07/full-text-of-senate-president-david-marks-address-at-the-mediaretreat-on-the-role-of-the-media-and-good-governance-in-nigeria.html(July 29/7/2012.) 